\title{
Atmospheric electricity as a proxy for air quality: Relationship between potential gradient and pollutant gases in an urban environment
}

\author{
H.G. Silva ${ }^{\text {a, * }}$, R. Conceição ${ }^{\text {a }}$, M.A.H. Khan ${ }^{b}$, J.C. Matthews ${ }^{b}$, M.D. Wright ${ }^{b}$, \\ M. Collares-Pereira ${ }^{\mathrm{a}}$, D.E. Shallcross ${ }^{\mathrm{b}}$ \\ ${ }^{a}$ Renewable Energies Chair, University of Évora, IIFA, Palácio do Vimioso, Largo Marquês de Marialva, 7002-554, Évora, Portugal \\ ${ }^{\mathrm{b}}$ Atmospheric Chemistry Research Group, School of Chemistry, University of Bristol, Cantock's Close, Bristol, BS8 1TS, UK
}

\section{A R T I C L E I N F O}

\section{Article history:}

Received 15 June 2016

Received in revised form

25 August 2016

Accepted 28 August 2016

Available online 17 September 2016

\section{Keywords:}

Air pollution

Trace gases

Particulate matter

Atmospheric electric potential gradient

\begin{abstract}
A B S T R A C T
A relationship between Trace Gases (TG), $\mathrm{NO}_{\mathrm{x}}, \mathrm{SO}_{2}, \mathrm{O}_{3}$, and the Atmospheric Electric Potential Gradient (PG), through Ion/Particulate Matter (PM) interaction, is established in the urban environment of the city of Lisbon (Portugal). Analysis was restricted to 1988-1990, when simultaneous measurements of PG and TG were taken. Reasonable linear relationships between PG and TG concentrations have been found. A formulation relating PG with TG concentrations allows the estimation of constants of proportionally between TG-PM to be $\sim 50 \mathrm{~cm}^{-3} \mathrm{ppb}^{-1}$; which are similar to the values found in direct TG-PM measurements in UK cities, validating the present results.
\end{abstract}

() 2016 Elsevier B.V. All rights reserved.

\section{Introduction}

Air pollution can be defined as the presence of pollutants, such as nitrogen oxides $\left(\mathrm{NO}_{\mathrm{x}}\right)$, sulphur dioxide $\left(\mathrm{SO}_{2}\right)$, ozone $\left(\mathrm{O}_{3}\right)$, carbon monoxide (CO) and particulate matter (PM) in the air, which can cause negative effects on human health and vegetation [8]. Emissions of these pollutants can lead to a complex series of physical and chemical transformations in urban and regional areas [26]. The main source of $\mathrm{NO}_{\mathrm{x}}$ in an urban environment is fossil fuel combustion originating from both stationary sources (i.e. power generation) and mobile sources (i.e. transport), while minor natural sources can include bacteria, volcanic action and lightning and noncombustion anthropogenic processes (e.g. $\mathrm{HNO}_{3}$ manufacture, welding processes and the use of explosives). The annual mean concentrations of $\mathrm{NO}_{2}$ (the major component of $\mathrm{NO}_{\mathrm{x}}$ ) in urban areas are generally found to be between 20 and $90 \mu \mathrm{gm}^{-3}(\sim 10-48 \mathrm{ppb})$, with peaks occurring twice a day as a consequence of rush hour traffic [27]. In urban areas, $\mathrm{SO}_{2}$ is emitted predominantly from fossil fuel combustion at power plants, residential activities (e.g.

\footnotetext{
* Corresponding author.

E-mail address: hgsilva@uevora.pt (H.G. Silva).
}

heating), traffic, and other industrial facilities, as well as from shipping near ports and coastal or inland shipping routes [7]. Other minor sources of $\mathrm{SO}_{2}$ include smelting, manufacturing of sulphuric acid, conversion of wood pulp to paper, incineration of refuse and extraction of elemental sulphur from ore. The annual urban mean concentrations of $\mathrm{SO}_{2}$ in Europe and the US oscillated between 10 and $30 \mu \mathrm{gm}^{-3}(\sim 3-12 \mathrm{ppb})[25] . \mathrm{O}_{3}$ is an important photo-oxidant that is produced from $\mathrm{NO}_{\mathrm{x}}$ catalysed photochemistry throughout the troposphere (e.g. Ref. [19]. Other photochemical reactions can produce a number of oxidants including peroxyacetyl nitrate as well as aldehydes, formic acid, and an array of short-lived radicals, which can produce and build up $\mathrm{O}_{3}$ downwind of urban areas. The maximum level of $\mathrm{O}_{3}$ observed in urban areas is well above $100 \mathrm{ppb}$ (e.g. Ref. [16]). PM in urban areas is mainly composed of metals, organic compounds, materials of biological origin and elemental carbon (e.g. Ref. [39]. Particulates can be classified as either primary or secondary, according to their origin. Primary particulates are those emitted directly to the atmosphere, while secondary particulates are those formed by reactions involving other pollutants. In the urban context, most secondary PM occur as sulphates and nitrates formed from reactions involving $\mathrm{SO}_{2}$ and $\mathrm{NO}_{\mathrm{x}}$, with typical annual mean values between 10 and $40 \mu \mathrm{g} \mathrm{m}^{-3}$ (black smoke method) or 50-150 $\mathrm{g} \mathrm{m} \mathrm{m}^{-3}$ (gravimetric method) [33]. At the sub- 
micron fraction $\left(\mathrm{PM}_{1}\right)$, there is often a significant contribution from secondary organic aerosol (SOA) as highlighted by Ref. [22].

In atmospheric electricity, a global electrical circuit is evidenced by a measurable atmospheric electric potential gradient at the Earth's surface, usually referred to as Potential Gradient $\left(\mathrm{PG}^{1}\right)$. Global thunderstorm activity transfers charge to the ionosphere, which returns to the ground by means of an air-Earth current through air; weakly ionised due to the presence of cluster-ions produced by solar and cosmic rays and ground based radiation. PG typically has a magnitude between 100 and $200 \mathrm{~V} \mathrm{~m}^{-1}$ in fair weather, but can be affected by sources of space charge, such as charged clouds or local sources of ions [14]. The effect of air pollutants, specifically particulate matter (PM), on the atmospheric PG is one of the most successful and largely explored applications of atmospheric electricity. Recent publications by the authors review this in detail; the interested reader is referred to these publications [35-37]. The basic physics of this process is summarized as follows: an increase in PM concentration depletes ions in the atmosphere, reducing the air conductivity and hence (according to Ohm's law) increasing PG. Of particular interest has been the ability to use historical records of PG since the industrial revolution [2] to retrieve pollution dynamics and smoke estimates [15]. More recently, attention has been given to the possibility of assessing smoke plume dynamics by combining PG measurements with HYSPLIT particle trajectory modelling [6].

To date, much less attention has been given to the relationship between Trace Gases (TG) and PG. In the literature the most prominent publications on this subject are those by Guo and coauthors, $[9,10]$. In these papers, those authors state that PG can be simultaneously a proxy of both PM and TG; the argument given to justify this is that both TG and PM influence the PG, but according to different mechanisms. The linear relationship between PG and PM is well established and has been described earlier. In the case of TG, the linear influence on PG is justified as TG contribute to the increase of the ion recombination rate, $\alpha[9,10]$. This results in a net reduction of ion production, that consequently reduces the air conductivity and therefore increases PG; explaining the PG-TG relationship. A detailed discussion of ion recombination is beyond the scope of the present work, but the interested reader is referred to seminal works on atmospheric ions available in the literature, e.g. Ref. [1]. Furthermore, this mechanism has been intensively debated as ion recombination is considered to be a key aspect in particle formation (e.g. the CLOUD experiments at CERN [20], and references therein) but it is the current view that there is no direct relationship between TG concentration and PG. The observed statistical correlation for PG and TG found in the work of Guo and coauthors $[9,10]$ is considered to result from an indirect relation; TG are proportional to PM and as PM influences PG a relation appears to hold between PG and TG. Proportionality of TG and PM concentrations has been shown in a number of different studies undertaken in urban environments. Among which [23], analysed data from Manchester, Birmingham and Edinburgh (UK) and found reasonable values of proportionality, $\sim 50 \mathrm{~cm}^{-3} \mathrm{ppb}^{-1}$, for PM and TG concentrations. Therefore, empirical evidence justifies the assumption of a linear relationship between TG concentrations and atmospheric PG measured at ground level.

The present work aims to clarify the linear relationship between PG and TG concentration, mediated by PM, as observed by

\footnotetext{
${ }^{1}$ PG is defined as the vertical component of the surface atmospheric electric field, $E_{z}$, by definition this field is negative in fair-weather days (field vector directed downwards). The convention used for PG, in order to have positive values for fairweather days, is to define $P G=-E_{z}$. This definition has been used from the beginning of atmospheric electricity and details can be found at [5].
}

Refs. $[9,10]$. A linear proportionality is assumed between PM and TG, following observations by Ref. [23]; and the formulation derived by Ref. [15]; is adapted to describe the linear relationship between PG and PM. With these assumptions a simple formula is derived relating PG-TG; which is shown to be linear. This formula is tested against observations in Lisbon, Portugal (1988-1990) and reasonable results are found which are supportive of the indirect PG-TG relation, clarifying this long-standing issue.

\section{Theoretical background and formulation}

The theoretical framework for the approach used here follows a similar method outlined in previous work by the authors [36]. Atmospheric small ions (clusters of molecules around a central ion) are produced by ionisation of air molecules, mainly by cosmic rays or radioactive decay [13]. A steady-state equation for ion formation and loss in the presence of PM was derived by Ref. [18] and is expressed as:

$q-\alpha n^{2}-\beta_{a} Z_{a} n=0$.

Where $n$ is the mean ion concentration, $q$ is the ion production rate (this is assumed to be $q \sim 10 \mathrm{~cm}^{-3} \mathrm{~s}^{-1}$ ), $\alpha$ is the ion recombination rate, $\beta_{a}$ is the effective ion-PM attachment coefficient for the PM size distribution in question, and $Z_{a}$ is PM number concentration. Eq. (1) neglects the positive to negative ion imbalance, as it is assumed a quasi-equilibrium state perturbed by the presence of PM. To relate urban PG measurements with TG, it is considered that most of the atmospheric ion loss is caused by ion-PM attachment and not by ion recombination; this assumption is validated by the work of [38]. The solution to this equation is straightforward:

$n=\frac{1}{2 \alpha}\left[\sqrt{\left(\beta_{a} Z_{a}\right)^{2}+4 \alpha q}-\beta_{a} Z_{a}\right]$.

For cases with relatively high PM concentration $\left(\sim 3000 \mathrm{~cm}^{-3}\right)$, such as would be expected in urban environments, Eq. (2) can be expanded in a Taylor series to yield a simple relationship between ion number concentration and PM number concentration:

$n \approx \frac{q}{\beta_{a} Z_{a}}$.

Details of this derivation can be found in Ref. [36]. With Eq. (3) the atmospheric electric conductivity can be written as:

$\sigma_{t}=2 \mu_{m} e n \approx \frac{2 \mu_{m} e q}{\beta_{a} Z_{a}}$

where $\mu_{m}$ is the mean electric mobility (the factor 2 is justified by the contribution of both positive and negative ions having similar mobilities) ande is the electron charge. The influence of charged PM on atmospheric electric conductivity is neglected due to their relatively low mobility [42]. Using (quasi-static) Ohm's law, it is possible to relate $P G$ with $\sigma_{t}$ by:

$P G=\frac{J_{z}}{\sigma_{t}} \approx \frac{J_{z}}{2 \mu_{m} e q} \beta_{a} Z_{a}$,

where $J_{z}$ is the air-Earth density current (usually considered to be $\sim 2 \mathrm{pAm}^{-2}$ ). Eq. (5) relates PG and $Z_{a}$ linearly and is similar to relationships found by Refs. [15,36] and [12]. Finally, supported by experimental observations by Ref. [23]; an empirical linear relation is used to relate $Z_{a}$ and TG concentration, $[X]$, of the type: 
$Z_{a} \approx Z_{0, X}+y_{X}[X]$

Where $y_{X}$ is the constant of proportionality between TG and the PM concentration (in units of $\mathrm{cm}^{-3} \mathrm{ppb}^{-1}$ ), $Z_{0, X}$ is the background PM constant, and $X$ is the concentration of either $\mathrm{NO}_{\mathrm{x}}, \mathrm{SO}_{2}$ or $\mathrm{O}_{3}$. A linear relation between TG and PG can be deduced as:

$P G \approx \frac{J_{z} \beta_{a} Z_{0, X}}{2 \mu_{m} e q}+\frac{J_{z} \beta_{a} y_{X}}{2 \mu_{m} e q}[X]$

Eq. (7) can be further modified by the use of Gunn's formula [11], $\beta_{a}=4 \pi k_{B} T \mu_{m} e^{-1} R_{a}$, to yield:

$P G \approx \frac{2 \pi J_{z} k_{B} T R_{a}}{e^{2} q} Z_{0, X}+\frac{2 \pi J_{z} k_{B} T R_{a}}{e^{2} q} y_{X}[X]$,

where $k_{B}$ is the Boltzmann constant; $T$ is the ambient temperature (set here as $293 \mathrm{~K}$ ); $R_{a}$ is the effective PM radius in the context of Hoppel's theory [18] which is assumed to be $R_{a}=0.1 \mu \mathrm{m}$. The formulation developed by Ref. [18] uses effective parameters to simplify the equation for ion balance in the presence of a more realistic aerosol size distribution. The parameters $Z_{0, X}$ and $y_{X}$ are determined for each TG according to the procedure described later.

\section{Data}

\subsection{Meteorology}

The former Portuguese Institute of Meteorology (IM) took meteorological measurements at the same station as PG was recorded (Lisbon Airport, Portugal: $38^{\circ} 46^{\prime} 32^{\prime \prime} \mathrm{N}, 9^{\circ} 07^{\prime} 30^{\prime \prime} \mathrm{W}$, Fig. 1). The data used in the present study were retrieved from the NNDC Climate Data Online website supported by NOAA. Two meteorological parameters were used: manually observed current weather (MW), which are important as precipitation and snow perturb PG (PG values having MW in the range of 50-99, corresponding to "precipitation at the station at the time of observation", were excluded); and wind direction (WD), because the PG has been shown to be strongly modulated by the nature of sources downwind $[36,37]$. According to the procedure in those two studies, TG and PG measurements are divided into four wind sectors:

1) $\mathrm{NW}, 270^{\circ} \leq \theta \leq 360^{\circ}$;

2) $\mathrm{NE}, 0 \leq \theta \leq 90^{\circ}$;

3) $\mathrm{SE}, 90 \leq \theta \leq 180^{\circ}$;

4) $\mathrm{SW}, 180^{\circ} \leq \theta \leq 270^{\circ}$.

Using the Portela station as a geographic reference, the main pollution sources (e.g. industry and traffic) were present within the Southern sectors whilst scarcer in Northern sectors. Portela was located in the Northern outskirts of Lisbon during the 1980s. The
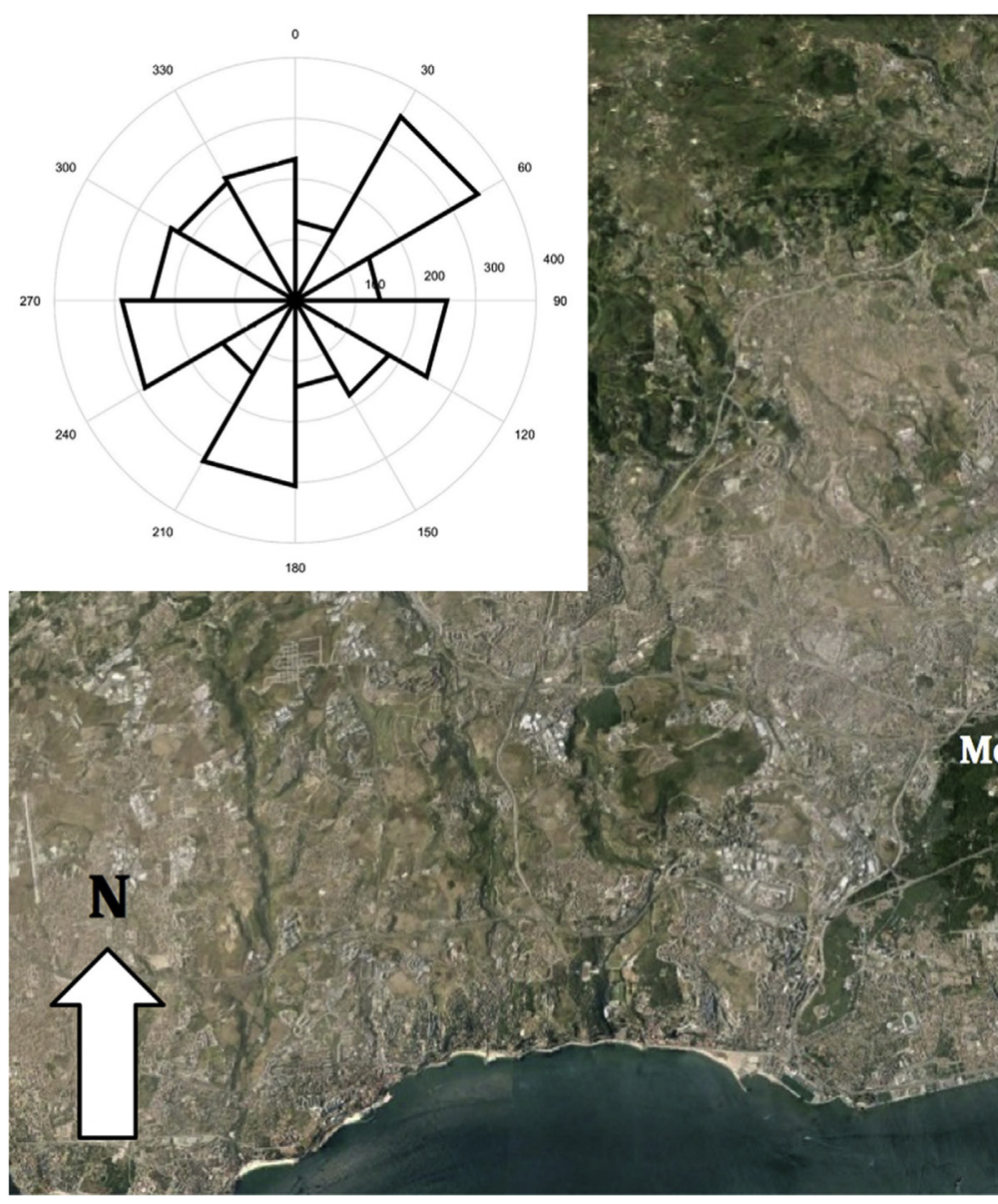
Tagus River basin and the Iberian Peninsula are located within the Eastern sectors whereas the Western sector is covered by the Atlantic Ocean. Significant industrial complexes existed in the late 1980s in the South margin of the Tagus River (Setubal region). The prevailing winds in Lisbon come from the NW and result from the Iberian thermal depression [36]. If the Rua de "O Século" station where TG measurements were taken, is used as a geographic reference Northern winds would carry pollution from the city, predominantly traffic, and the Southern winds would carry pollution from the industries mentioned previously.

\subsection{Potential gradient}

A Benndorf electrograph was coupled to a radioactive probe to equalize potential between the sensor and the air and to improve the time response of the electrograph. It was installed $1 \mathrm{~m}$ above the ground in a cement base at the Portela meteorological station and recorded PG. Its sensitivity was checked using an electronic electrometer with a standard voltage source between $\pm 200 \mathrm{~V}$; the same calibration procedure was used in all periods of operation. The paper records of the electrograph were digitalized at a later date [32]. Further details about the dataset can be found in Refs. [6,35,36]. In this study, data from 1988 to 1990 (restricted by the TG data) were used and values of PG between 0 and $300 \mathrm{~V} / \mathrm{m}$ were selected; these values are indicative of fair-weather conditions [5]. A detailed description of the WD dependence of the PG can be found in previous works $[36,37]$.

\subsection{Trace Gases}

The gas species, $\mathrm{NO}_{\mathrm{x}}, \mathrm{SO}_{2}, \mathrm{O}_{3}$, were measured in the air quality station located at Rua de "O Século" (Lisbon city centre, Portugal: $\left.38^{\circ} 42^{\prime} 44^{\prime \prime} \mathrm{N}, 9^{\circ} 08^{\prime} 51^{\prime \prime} \mathrm{W}\right)$ supported by the Lisbon Regional
Coordination and Development Commission (Fig. 1). The air quality station was located around $8 \mathrm{~km}$ NE from Portela station where PG was recorded. Measurements began in 1988 but during most of that year, it was in a trial stage and the validated data available did not reach $75 \%$, only validated data are used here. The operation of the station has continued (with several upgrades) to the present day, but only the years 1988-1990 are considered here as PG records end in 1990. $\mathrm{NO}_{\mathrm{x}}, \mathrm{SO}_{2}$, and $\mathrm{O}_{3}$ were measured by chemiluminescence (Environment AC 3OM), UV fluorescence, and ultraviolet absorption (Dasibi 1003 RS), respectively. Unfortunately, no reliable CO and PM measurements exist from this station. $\mathrm{NO}_{\mathrm{x}}, \mathrm{SO}_{2}$ and $\mathrm{O}_{3}$ were separated according to wind direction at the Portela station. The reason that wind directions at Portela were chosen instead of at Rua de "O Século" was because the main focus of the present work is to compare the PG measurements with the TG. However, if Lisbon climatology is taken into account [35,36], the winds in Portela can be considered as representative of those in the city centre.

\section{Results and discussion}

TG concentrations are represented in histograms according to the wind sectors, defined previously, in Fig. 2, it can be seen that $\mathrm{NO}_{\mathrm{X}}, \mathrm{SO}_{2}$ and $\mathrm{O}_{3}$ have similar distributions for each wind sector and their values occur predominantly in the $0-200$ ppb range. Northern wind quadrants are more numerous than Southern quadrants as a result of the dominant Northern winds in Lisbon, the so-called Nortada regime [36]. The mean concentrations of $\mathrm{NO}_{\mathrm{x}}, \mathrm{SO}_{2}$ and $\mathrm{O}_{3}$ tend to be higher for Northern winds, especially NE, as compared with Southern ones, in particular SW (Table 1). Additional statistical parameters can also be found in Table 1. These are consistent with the fact that Northern winds carry higher $\mathrm{NO}_{\mathrm{x}}$ and $\mathrm{SO}_{2}$ concentrations than Southern ones, this implies that most of these two pollutants are generated by urban activity (mainly traffic) in the
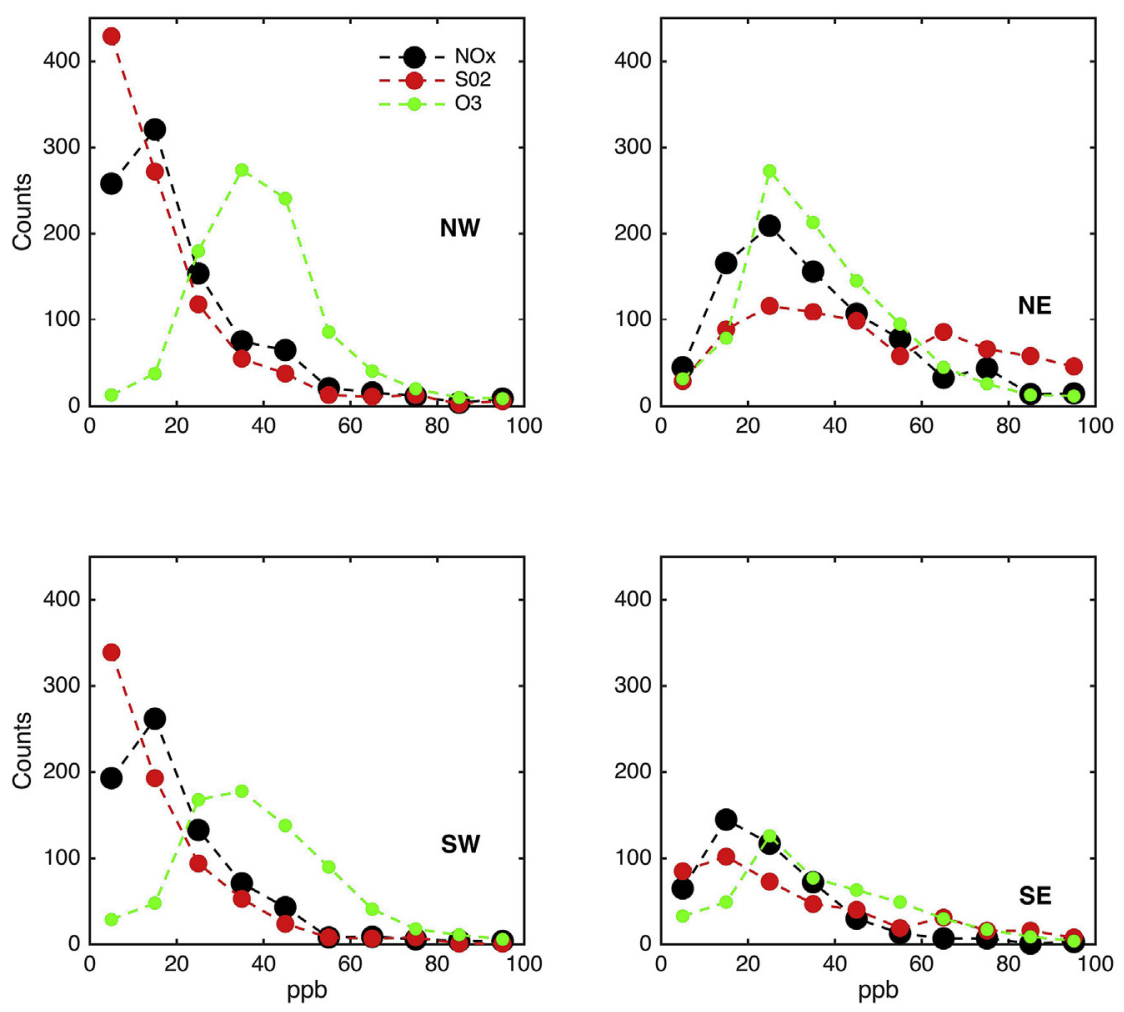

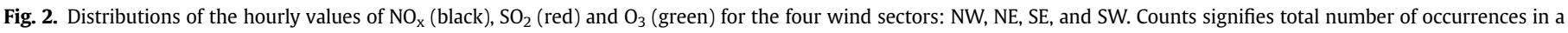
given bin. (For interpretation of the references to colour in this figure legend, the reader is referred to the web version of this article.) 
Table 1

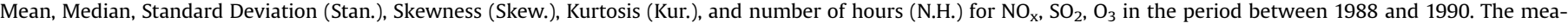
surements are divided according to the wind direction in Portela: NW, NE, SE, and SW.

\begin{tabular}{|c|c|c|c|c|c|c|c|c|c|c|c|c|}
\hline & \multicolumn{3}{|l|}{ NW } & \multicolumn{3}{|l|}{$\mathrm{NE}$} & \multicolumn{3}{|l|}{ SE } & \multicolumn{3}{|l|}{ SW } \\
\hline & $\mathrm{NO}_{\mathrm{x}}$ & $\mathrm{SO}_{2}$ & $\mathrm{O}_{3}$ & $\mathrm{NO}_{\mathrm{x}}$ & $\mathrm{SO}_{2}$ & $\mathrm{O}_{3}$ & $\mathrm{NO}_{\mathrm{x}}$ & $\mathrm{SO}_{2}$ & $\mathrm{O}_{3}$ & $\mathrm{NO}_{\mathrm{x}}$ & $\mathrm{SO}_{2}$ & $\mathrm{O}_{3}$ \\
\hline Mean $^{a}$ & 26.34 & 18.09 & 55.55 & 39.97 & 74.30 & 42.03 & 25.85 & 43.52 & 42.48 & 21.39 & 17.33 & 42.00 \\
\hline Median $^{a}$ & 16.00 & 10.48 & 39.24 & 31.00 & 57.64 & 34.90 & 21.00 & 26.20 & 33.35 & 16.00 & 10.48 & 37.28 \\
\hline Stan ${ }^{\mathrm{a}}$ & 32.95 & 21.65 & 116.87 & 30.76 & 61.73 & 31.07 & 20.07 & 48.65 & 41.45 & 20.34 & 22.41 & 26.05 \\
\hline Skew. & 3.59 & 3.73 & 8.64 & 2.56 & 2.10 & 3.72 & 2.45 & 2.61 & 6.99 & 3.26 & 4.79 & 3.58 \\
\hline Kurt. & 18.98 & 24.78 & 8.64 & 14.56 & 10.49 & 22.57 & 11.54 & 11.90 & 82.34 & 19.41 & 37.93 & 27.15 \\
\hline N.H. & 975 & 971 & 954 & 913 & 992 & 969 & 468 & 482 & 474 & 744 & 738 & 752 \\
\hline
\end{tabular}

a These parameters have units in $\mathrm{ppb}$.

city instead of the industrial regions in the Southern wind sectors, which are known to be significant sources of PM [36,37]. Further evidence that this is the case is that the NE sector has the highest mean values of the four sectors for both $\mathrm{NO}_{\mathrm{x}}$ and $\mathrm{SO}_{2}$. In $\mathrm{Rua}$ de "O Século", NE winds are the most likely to carry air pollution from the city to the station and show a stronger relationship with PG, as will be shown later. The finding that Northern winds have higher concentrations of $\mathrm{NO}_{\mathrm{x}}$ and $\mathrm{SO}_{2}$ reinforces the importance of urban activity on the concentrations of these gases within the city centre. The NW sector has the highest concentrations of $\mathrm{O}_{3}$ and the remaining wind sectors have similar values, this is likely to be due to the presence of Serra de Monsanto, Fig. 1, a densely forested part of NW Lisbon and a source of volatile organic compounds (VOC) which can be responsible for the generation of $\mathrm{O}_{3}$ through a positive feedback process described in detail in Ref. [28] but noted in several studies elsewhere, where a large source of reactive VOCs exacerbates ozone production in the presence of significant $\mathrm{NO}_{\mathrm{x}}$ emissions (e.g. Ref. [17].
Lomb-Scargle periodograms [31,35] for each of the three gases were calculated using the Bret [34] implementation and are presented in Fig. 3. These periodograms indicate dominant cycles in uneven time-series, in this case these are the annual ( 1 year) and weekly (7 days) periods. A weekly periodicity is commonly attributed to anthropogenic action [40] as during a working day there is a greater amount of human activity (predominantly traffic) producing more pollution than at weekends. For that reason, work days have higher TG concentrations than weekends causing a weekly periodicity. Therefore, the weekly cycle has been used as a proxy to infer an anthropogenic influence on PG [35]; a stronger weekly cycle implies greater anthropogenic influence and with it more pollution. Fig. 3 confirms a source with a strong weekly cycle prevailing in the Eastern wind sectors, NE and SE indicating more sources of pollution in that region in accordance with the previous statistical description. The weekly periodicity points towards traffic as the main source for these gas species [35]. An annual cycle is generally present in all wind sectors for all three gas species, this
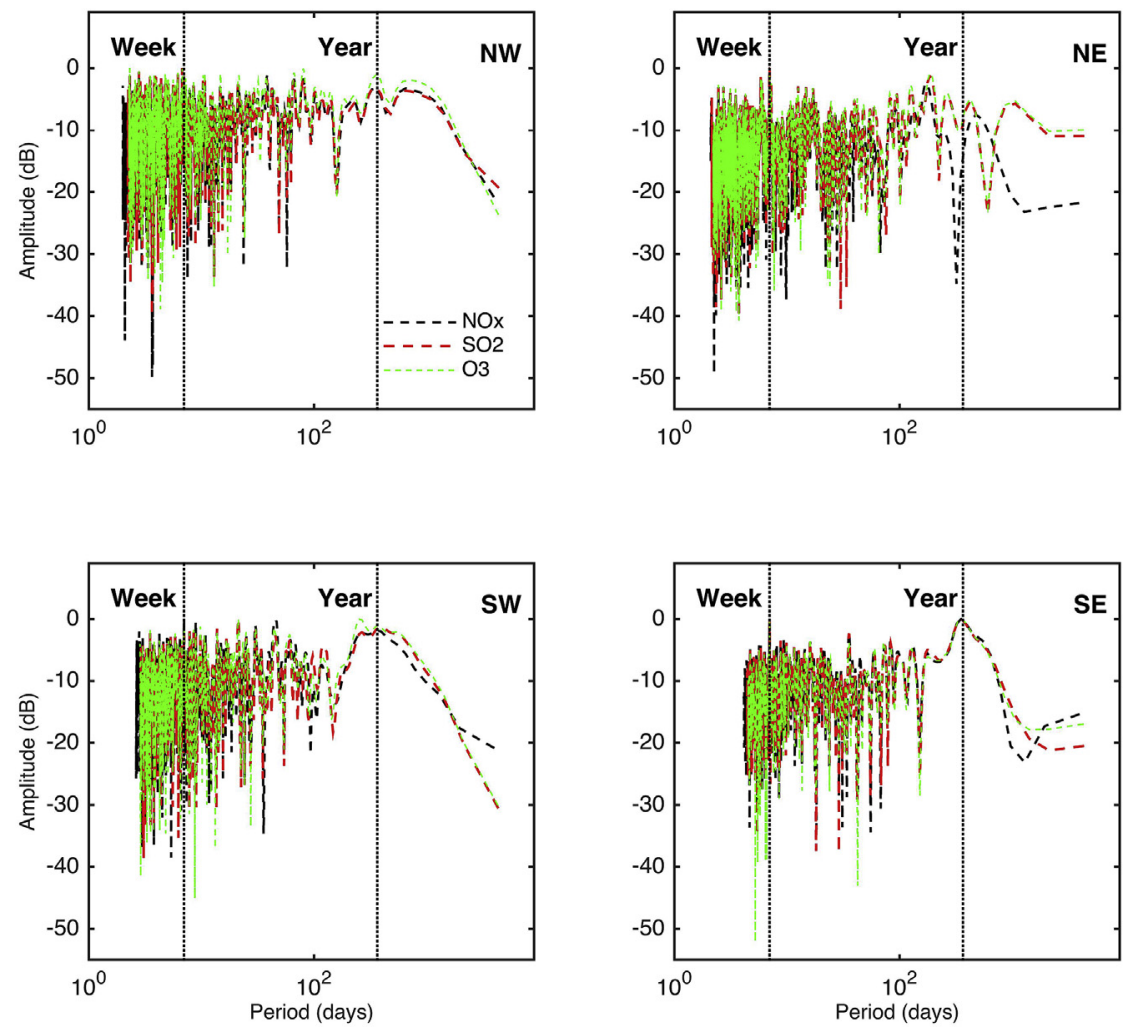

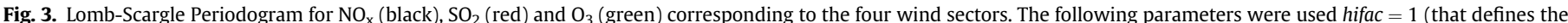

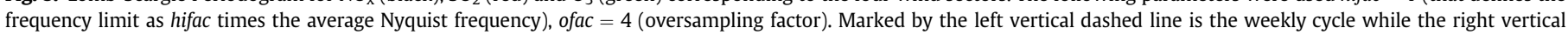
dashed line denotes the annual cycle. (For interpretation of the references to colour in this figure legend, the reader is referred to the web version of this article.) 
cycle also appears in PG [35], and is attributable to seasonal meteorological variations imposing a strong modulation on TG. To further understand the dynamics of TG, boxplots representing the daily variation of their concentrations are shown in Fig. 4. Both $\mathrm{NO}_{\mathrm{x}}$ and $\mathrm{SO}_{2}$ show two main peaks: one at $\sim 8$ UTC and another at $\sim 18$ UTC which correspond to rush hours in Lisbon and are consistent with the earlier finding that NE wind sectors show higher concentrations. $\mathrm{O}_{3}$ shows a single peak around 14 UTC (NW wind sectors show higher concentrations) which implies higher levels of photochemical activity due to the increase in solar radiation at mid solar day [24] that in Lisbon corresponds to 14 UTC.

To identify the possible relationship between TG and PG three steps are taken. First, PG values are separated into TG concentration bins with a given width, $\Delta[X]=10 \mathrm{ppb}$, from $[X]_{i n i}=0 \mathrm{ppb}$ up to $[X]_{\text {end }}=90 \mathrm{ppb}$. The condition for each $j$-bin is:

$[X]_{i n i}+(j-1) \Delta[X]<[X](j) \leq[X]_{i n i}+j \Delta[X]$,

The choice of $\Delta[X]$ has been made as a trade-off between the statistical representativeness of each bin and ensuring a sufficient number of values to enable statistical confidence in the analysis. Second, mean values (standard deviations are represented as error bars) of PG for each TG concentration bin have been calculated and are represented as a function of the mean value of the gas concentration for that bin, the results are shown in Fig. 5. Third, Eq. (8) is used to fit the resulting values.

A good linear relationship between PG and TG is found in the four wind directions with goodness of fit, $r^{2}$, close to 1 , the fitting parameters, $Z_{0, X}$ and $y_{X}$, are summarized in Table 2. Better fits (in terms of $r^{2}$ ) are found for the Northern wind sectors, NW and NE, for the three gas species and PG. The constants of proportionality for NW are found to be $y_{\mathrm{NO} X}=27.38 \mathrm{~cm}^{-3} \mathrm{ppb}^{-1}, y_{\mathrm{SO}_{2}}=45.73$ $\mathrm{cm}^{-3} \mathrm{ppb}^{-1}$, and $y_{03}=35.14 \mathrm{~cm}^{-3} \mathrm{ppb}^{-1}$. However, the values for NE are: $y_{\mathrm{NOx}}=55.40 \mathrm{~cm}^{-3} \mathrm{ppb}^{-1}, y_{\mathrm{SO} 2}=21.32 \mathrm{~cm}^{-3} \mathrm{ppb}^{-1}$, and $y_{03}=47.91 \mathrm{~cm}^{-3} \mathrm{ppb}^{-1}$. Uncertainties in these parameters are $<0.01 \mathrm{~cm}^{-3} \mathrm{ppb}^{-1}$ (a pessimistic evaluation was used). These are very similar to the values $\left(\sim 50 \mathrm{~cm}^{-3} \mathrm{ppb}^{-1}\right)$ found by Ref. [23] who measured $\mathrm{CO}, \mathrm{NO}_{\mathrm{x}}$ and $\mathrm{PM}$ number concentration in urban environments. Those authors undertook measurements in three busy UK cities, Manchester, Birmingham and Edinburgh, where road vehicle exhausts were the major sources of $\mathrm{CO}, \mathrm{NO}_{\mathrm{x}}$ and $\mathrm{PM}$; similar to what happens in Lisbon. Actually, Lisbon in the 1980s was characterized by very heavy traffic that had (and still has) similarities with the urban environmental conditions of the three UK cities mentioned earlier. For that reason, it should be expected that a similar proportionality between PM and TG would be found in Lisbon. Nevertheless, finding this same proportionality between PM and TG in Lisbon as in the three UK cities by means of PG measurements is noteworthy and constitutes the most relevant result from the present study. It presents new possibilities in the use of PG measurements for air quality (in particular, PM) assessment in urban environments, and strengthens the points previously discussed in this context $[35,36]$.

It is important to highlight that NE winds tend to show a better $r^{2}$ in the relationship between PG and TG, this is tentatively explained by the fact that the NE winds include air transported from Portela (where PG is measured) to Rua de "O Século" (where TG are measured) and for that reason a closer relationship between
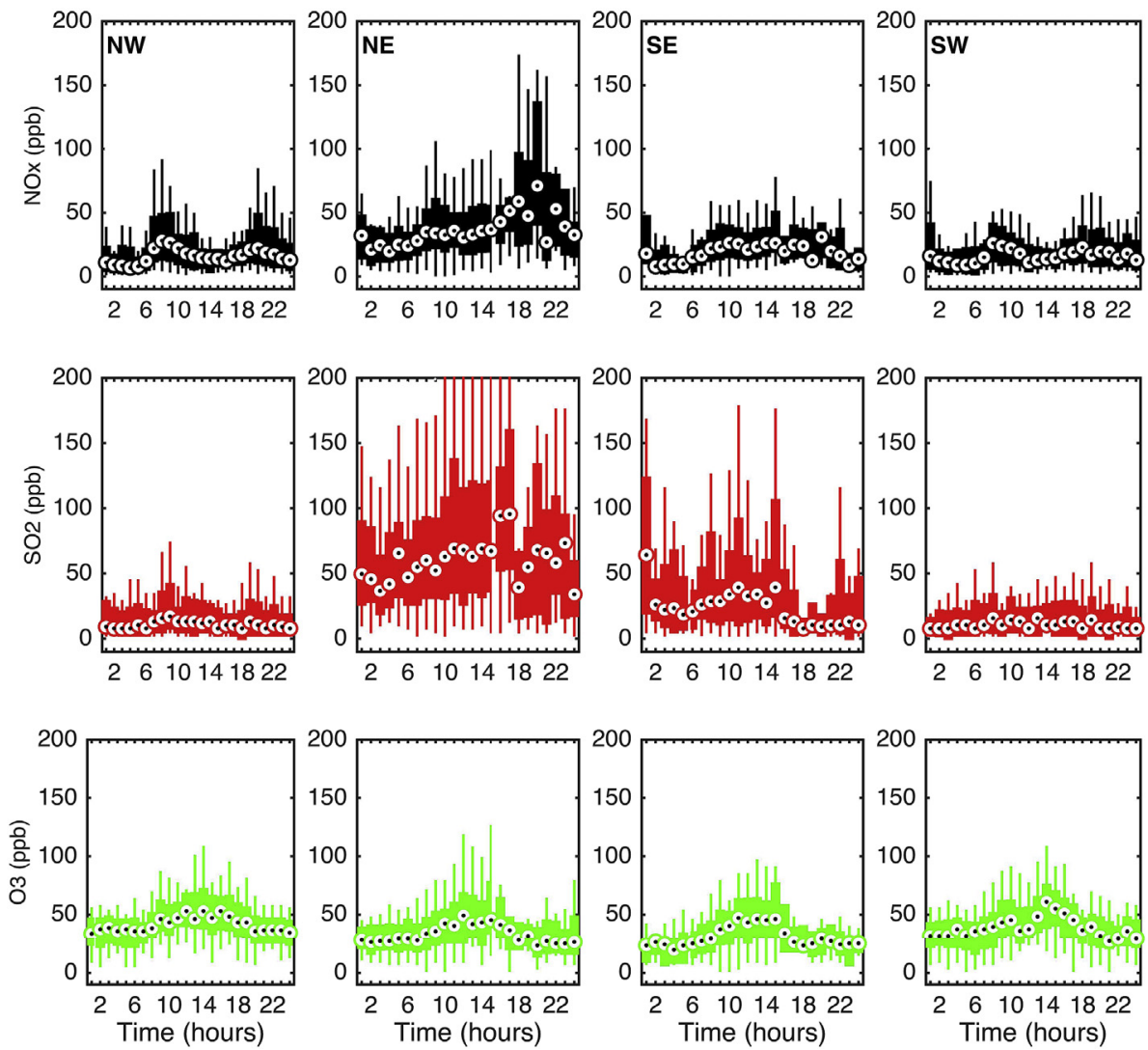

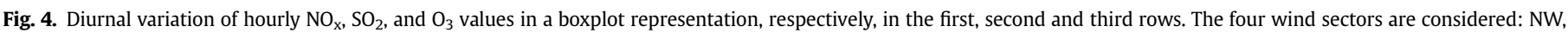

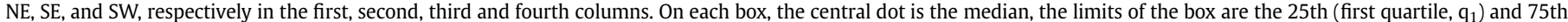

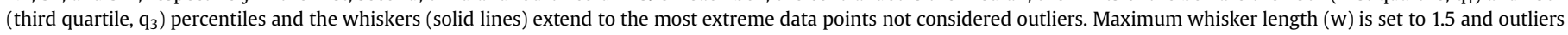
are defined to be larger than $\mathrm{q}_{3}+\mathrm{w}\left(\mathrm{q}_{3}-\mathrm{q}_{1}\right)$ or smaller than $\mathrm{q}_{1}-\mathrm{w}\left(\mathrm{q}_{3}-\mathrm{q}_{1}\right)$. 

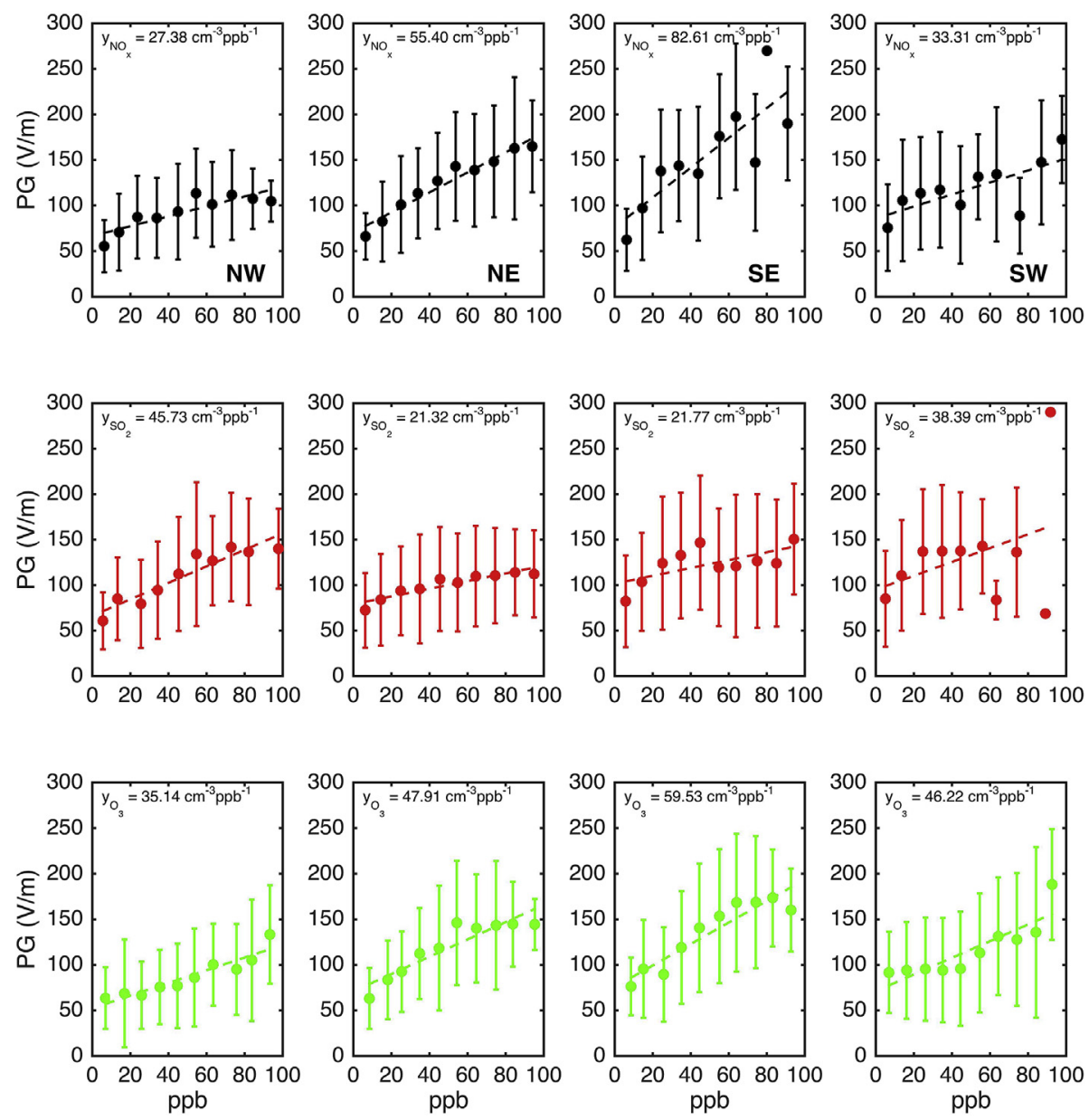

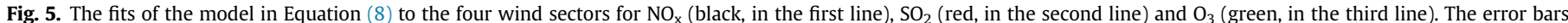

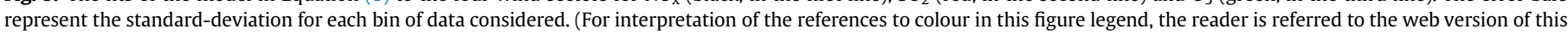
article.)

these variables is unsurprising. On the other hand, the background values of the PM number concentration, $Z_{0, X}$, seem to be higher for the Southern wind sectors than Northern sectors, and seem consistent with the results found previously by Refs. [36,37]; as the main sources of PM would be likely to be present in the Southern part of the Tagus River where intense industrial activity existed in the 1980s. The presence of this source of pollution, which is substantially different from traffic, may also explain the weaker agreement (lower values of $r^{2}$ ) between PG and TG in following a linear relationship for the Southern winds, as PM and TG would have different sources and therefore a proportional relationship would no longer be expected. This assumption of proportionality is based on the indirect linear relationship of PG with TG, via PM, and if the proportionality does not hold, the PG-
TG relationship also will not hold. It may also be due to a less favourable air transport from Rua de "O Século" (where TG are measured) to Portela (where PG is measured) and to a significantly lower number of recorded values (as confirmed by the number of hours, N.H., Table 1 ). The constants of proportionality for SE are found to be $y_{\mathrm{NO} x}=82.61 \mathrm{~cm}^{-3} \mathrm{ppb}^{-1}, y_{\mathrm{SO} 2}=21.77$ $\mathrm{cm}^{-3} \mathrm{ppb}^{-1}$, and $y_{03}=59.53 \mathrm{~cm}^{-3} \mathrm{ppb}^{-1}$. The values for SW are: $y_{\mathrm{NO} x}=33.31 \mathrm{~cm}^{-3} \mathrm{ppb}^{-1}, y_{\mathrm{SO} 2}=38.39 \mathrm{~cm}^{-3} \mathrm{ppb}^{-1}$, and $y_{03}=46.22$ $\mathrm{cm}^{-3} \mathrm{ppb}^{-1}$. Estimated errors are again $<0.01 \mathrm{~cm}^{-3} \mathrm{ppb}^{-1}$. Again these values are close to the values found by Ref. [23] and provide a reasonable level of robustness in the use of PG measurements as a proxy of PM in urban environments.

To further evidence this, a scatter plot representation of $\mathrm{SO}_{2}$ as a function of $\mathrm{NO}_{\mathrm{x}}$ with the corresponding values of $\mathrm{PG}$ represented as

Table 2

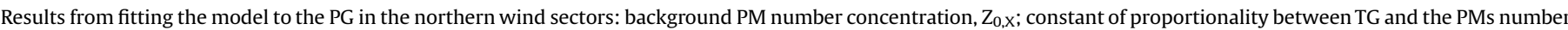
concentration, $\mathrm{y}_{[\mathrm{X}]}$. The goodness of the fit is also given, $r^{2}$. It is assumed that particle radius is $\mathrm{R}_{\mathrm{a}}=0.1 \mu \mathrm{m}$.

\begin{tabular}{|c|c|c|c|c|c|c|c|c|c|c|c|c|}
\hline & \multicolumn{3}{|l|}{ NW } & \multicolumn{3}{|l|}{$\mathrm{NE}$} & \multicolumn{3}{|l|}{$\mathrm{SE}$} & \multicolumn{3}{|l|}{ SW } \\
\hline & $\mathrm{NO}_{\mathrm{x}}$ & $\mathrm{SO}_{2}$ & $\mathrm{O}_{3}$ & $\mathrm{NO}_{\mathrm{x}}$ & $\mathrm{SO}_{2}$ & $\mathrm{O}_{3}$ & $\mathrm{NO}_{\mathrm{x}}$ & $\mathrm{SO}_{2}$ & $\mathrm{O}_{3}$ & $\mathrm{NO}_{\mathrm{x}}$ & $\mathrm{SO}_{2}$ & $\mathrm{O}_{3}$ \\
\hline$z_{0, x^{a}}$ & 3360 & 3350 & 2642 & 3563 & 3997 & 3585 & 3844 & 5134 & 3825 & 4331 & 4802 & 3589 \\
\hline $\mathrm{y}_{[\mathrm{XX}]^{\mathrm{b}}}$ & 27.38 & 45.73 & 35.14 & 55.40 & 21.32 & 47.91 & 82.61 & 21.77 & 59.53 & 33.31 & 38.39 & 46.22 \\
\hline$R^{2}$ & 0.9992 & 0.998 & 0.9999 & 0.9994 & 0.9999 & 0.999 & 0.95 & 0.998 & 0.998 & 0.99 & 0.92 & 0.996 \\
\hline
\end{tabular}

a These parameters have units in $\mathrm{cm}^{-3}$ and estimated errors $<1 \mathrm{~cm}^{-3}$.

b These parameters have units in $\mathrm{cm}^{-3} \mathrm{ppb}^{-1}$ and uncertainties $<0.01 \mathrm{~cm}^{-3} \mathrm{ppb}^{-1}$ 

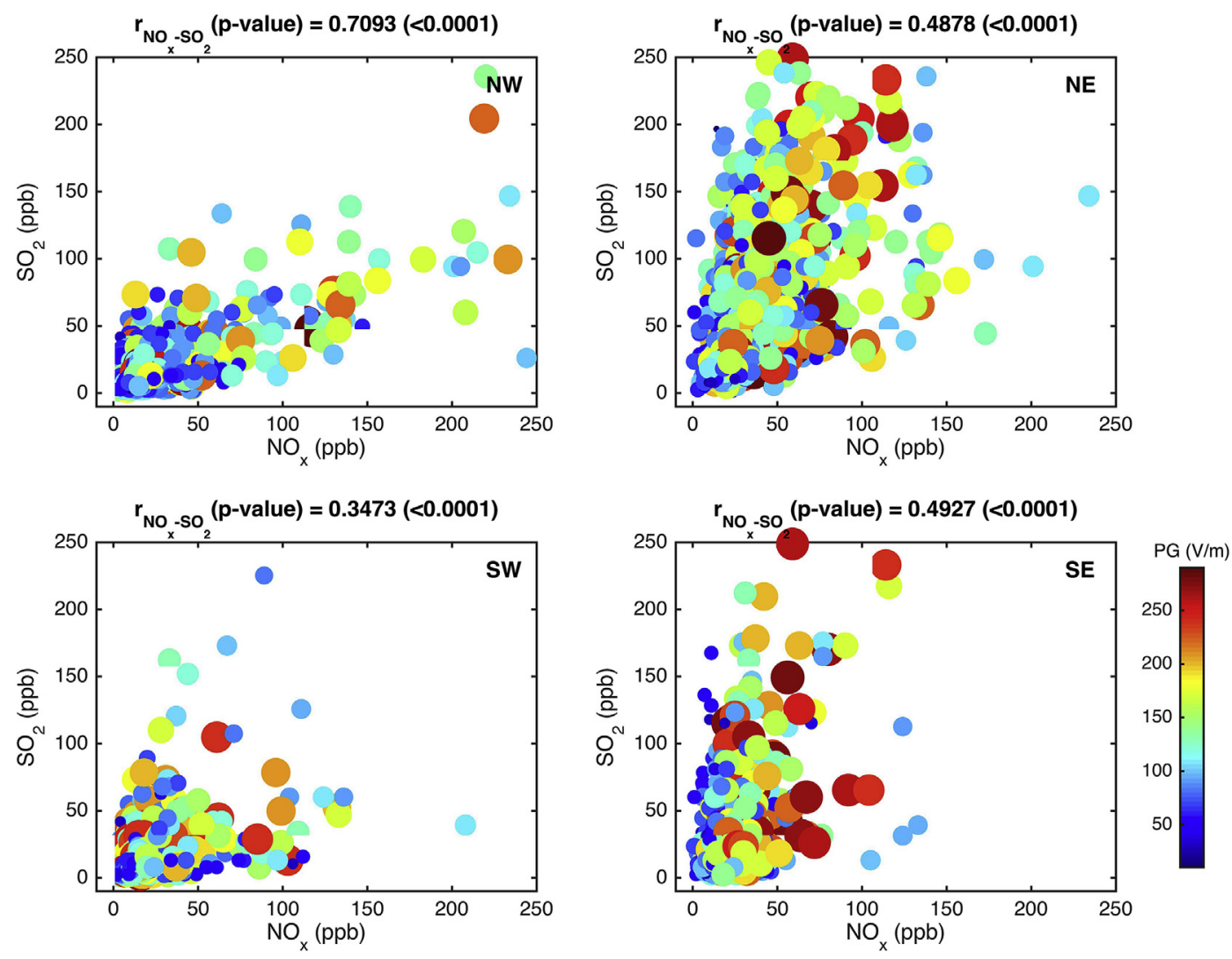

Fig. 6. Scatter plots of $\mathrm{SO}_{2}$ as a function of $\mathrm{NO}_{\mathrm{x}}$ with the corresponding values of $\mathrm{PG}$ represented as a colour gradient, for each wind sector: $\mathrm{NW}$, $\mathrm{NE}$, $\mathrm{SE}$, and $\mathrm{SW}$.

a colour gradient is now presented in Fig. 6. Scatter plots are frequently used in environmental sciences to understand the interrelationship between three different atmospheric constituents, e.g. $\mathrm{NO}_{x}, \mathrm{O}_{3}$ and $\mathrm{HCOOH}$ (e.g. Ref. [4]. In Fig. 6 it is visible that reasonable relationships between $\mathrm{NO}_{\mathrm{x}}$ and $\mathrm{SO}_{2}$ are found considering all PG values: correlation valuesr $\mathrm{SO}_{2}, \mathrm{NO}_{x}$, ranging from $\sim 0.71$ to $\sim 0.35$ and $p$-values $<0.0001$. Interestingly, if the $\mathrm{NO}_{\mathrm{x}}-\mathrm{SO}_{2}$ relationship is analysed for values of PG corresponding to PG $>150 \mathrm{~V} / \mathrm{m}$ (not shown) the correlation values, $r_{\mathrm{NO}_{x}, \mathrm{SO}_{2}}$, are increased by up to $12 \%$ and the opposite happens when considering PG $<150 \mathrm{~V} / \mathrm{m}$ (not shown). An increase in the $\mathrm{NO}_{\mathrm{x}}-\mathrm{SO}_{2}$ correlation is expected for polluted environments and this suggests that the condition PG $>150 \mathrm{~V} / \mathrm{m}$ corresponds to heavier pollution than $\mathrm{PG}<150 \mathrm{~V} / \mathrm{m}$. This confirms the possibility of using PG in urban environments as a proxy for pollution levels. Moreover, $\mathrm{SO}_{2}$ is an important secondary particle precursor via oxidation in the atmosphere to form sulphuric acid, $\mathrm{H}_{2} \mathrm{SO}_{4}$, which is thought to play a significant role in the formation of PM $[3,21,30,43]$ and through Eq. (5) it will influence the PG. It should be noted that although $\mathrm{SO}_{2}$ emissions in Europe have been reduced significantly over recent decades [41], sulphate still contributes significantly to PM mass [29]. At the time of data collection, $\mathrm{SO}_{2}$ emissions were much higher than present day levels and therefore may had a higher PM formation and consequently higher PG. This observation strengthens the possibility of using PG instead of PM when studying the relationship between particle and gaseous pollution, especially in the case of historical PG records, e.g, [2]. Coming back to Fig. 6, it can be found:

- NW wind sector has the highest $\mathrm{NO}_{\mathrm{x}}-\mathrm{SO}_{2}$ correlation $r_{\mathrm{NO}_{x}, \mathrm{SO}_{2}}=0.7093$, and the $\mathrm{NO}_{\mathrm{x}}, \mathrm{SO}_{2}$ concentrations are $150 \mathrm{ppb}$ (some exceptions are observed);
- $\mathrm{NE}$ wind sector shows a lower $\mathrm{NO}_{\mathrm{x}}-\mathrm{SO}_{2}$ correlation $r_{\mathrm{NO}_{x}, \mathrm{SO}_{2}}=0.4878$, and $\mathrm{SO}_{2}$ concentrations reaching $\sim 250 \mathrm{ppb}$, but the $\mathrm{NO}_{\mathrm{x}}$ remaining lower than $\sim 150 \mathrm{ppb}$;

- SE wind sector has a comparable behaviour with the NE sector, $\mathrm{NO}_{\mathrm{x}}-\mathrm{SO}_{2}$ correlation $r_{\mathrm{NO}_{\mathrm{x}}, \mathrm{SO}_{2}}=0.4927$ and $\mathrm{SO}_{2}<\sim 250 \mathrm{ppb}$ and $\mathrm{NO}_{\mathrm{x}}<\sim 150 \mathrm{ppb}$.

- $\mathrm{SW}$ wind sector has the lowest $\mathrm{NO}_{\mathrm{x}}-\mathrm{SO}_{2}$ correlations, $r_{\mathrm{NO}_{\mathrm{x}}, \mathrm{SO}_{2}}=$ 0.3473 but the $\mathrm{NO}_{\mathrm{x}}, \mathrm{SO}_{2}$ concentrations are $\sim 150 \mathrm{ppb}$ similar to the NW sector.

All the correlations have $p$-values $<0.0001$. It can also be observed, that generically higher concentrations of $\mathrm{NO}_{\mathrm{x}}$ and $\mathrm{SO}_{2}$ correspond to high PG values, reinforcing again the possible role of PG as a proxy of pollution. The most important conclusion that can be drawn from Fig. 6 is that the Eastern wind sectors, NE and SE, show evidence of an increase in PG (proportional to the PM number concentration) with $\mathrm{SO}_{2}$ concentrations (that reach $\sim 250 \mathrm{ppb}$ ) while the $\mathrm{NO}_{\mathrm{x}}$ levels remain below $\sim 150 \mathrm{ppb}$. Eastern wind sectors share the same characteristic of receiving land air masses that apparently have a more decisive rule in the $\mathrm{SO}_{2}, \mathrm{NO}_{\mathrm{x}}$ and $\mathrm{PG}$ relation, than the marine air masses that characterize Western wind sectors. This fact can be related with the fact that marine air masses transport small ions that tend to reduce the PG and the inverse happens with land air masses that bring dust and continental PM that tend to increase the PG.

\section{Conclusions}

This work presents a multidisciplinary study covering three different aspects in air pollution: PM, TG, and PG. Focus is given to the urban environment of the city of Lisbon (Portugal) in the late 
1980s, when traffic was the main source of pollution within the city. The data analysed, though historic, constitutes a unique opportunity for studying simultaneous TG and PG. A reliable linear relation is found between TG concentration and PG which is justified by a formula developed to explain it. Two noteworthy results have been found: the constant of proportionally between TG concentration and PM number concentration is estimated to be $\sim 50 \mathrm{~cm}^{-3} \mathrm{ppb}^{-1}$, similar to experimental studies that measured PM directly; and evidence of a possible influence of $\mathrm{SO}_{2}$ in $\mathrm{PM}$ formation for the SE wind sector is explored. These results are supportive of an indirect relationship between TG and PG mediated by PM. The present study considers PG measurements to relate TG with PM in an innovative way that could constitute a wide range of future applications regarding the use of Atmospheric Electricity as a tool for Air Quality monitoring.

\section{Acknowledgments}

Gratitude is expressed to Cláudia Serrano and Samuel Bárias for digitalizing the PG data recorded by Doctor Mário Figueira from the former Portuguese MetService, IM. Trace Gas data was provided by Luisa Nogueira from the Coordination and Regional Development Commission of Lisbon and Tagus Valley, CCDR-LVT. Discussions with Marta Melgão, Sérgio Pereira, Heitor Reis, Pavan Kulkarni, and Giles Harrison are recognized here. Researchers from the University of Évora acknowledge funding from the Portuguese Science and Technology Foundation (FCT) through the program Pest/OE/CTE/ UI0078/2014. Researchers from the University of Bristol acknowledge funding from the Leverhulme Trust through grant RPG-2014102 and Natural Environmental Research Council (NERC) through Grant No. NE/K01501X/1. Finally, the detailed review of the manuscript by one anonymous reviewer is gratefully acknowledged.

\section{References}

[1] R.V. Anderson, Atmospheric electricity in the real world - useful applications of observations which are perturbed by local effects, in: H. Dolezalek, R. Reiter (Eds.), Electrical Processes in Atmospheres, 1977, pp. 87-99. Steinkopff, (Darmstadt, Germany).

[2] K. Aplin, Smoke emissions from industrial western Scotland in 1859 inferred from Lord Kelvin's atmospheric electricity measurements, Atmos. Environ. 50 (2012) 373.

[3] M. Boy, M. Kulmala, T.M. Ruuskanen, M. Pihlatie, A. Reissell, P.P. Aalto, P. Keronen, M. Dal Maso, H. Hellen, H. Hakola, R. Jansson, M. Hanke, F. Arnold, Sulphuric acid closure and contribution to nucleation mode particle growth, Atmos. Chem. Phys. 5 (2005) 863-878.

[4] M.L. Breton, A. Bacak, J.B.A. Muller, P. Xiao, B.M.A. Shallcross, R. Batt, C.J. Percival, et al., Simultaneous airborne nitric acid and formic acid measurements using a chemical ionization mass spectrometer around the UK: analysis of primary and secondary production pathways, Atmos. Environ. 83 (2014) 166-175.

[5] J.A. Chalmers, Atmospheric Electricity, second ed., Pergamon Press, Oxford, 1967 (Section 2.7).

[6] R. Conceição, H.G. Silva, M. Melgão, K. Nicoll, R.G. Harrison, A.H. Reis, Transport of the smoke plume from Chiado's fire in Lisbon (Portugal) sensed by atmospheric electric field measurements. Air Quality, Atmos. Health 8 (2015) (2015), http://dx.doi.org/10.1007/s11869-015-0337-4.

[7] V. Eyring, I.S.A. Isaksen, T. Berntsen, W.J. Collins, J.J. Corbett, O. Endresen, R.G. Grainger, J. Moldanova, H. Schlager, D.S. Stevenson, Transport impacts on atmosphere and climate: Shipping, Atmos. Environ. 44 (2010) 4735-4771, http://dx.doi.org/10.1016/j.atmosenv.2009.04.059.

[8] J. Fleming, R. Stern, R.J. Yamartino, A new air quality regime classification scheme for $\mathrm{O}_{3}, \mathrm{NO}_{2}, \mathrm{SO}_{2}$ and PM10 observations sites, Atmos. Environ. 39 (33) (2005) 6121-6129, http://dx.doi.org/10.1016/j.atmosenv.2005.06.039.

[9] Y. Guo, N.N. Barthakur, S. Bhartendu, The spectral relationships between atmospheric electrical conductivity and air pollution in urban conditions, J. Geophys. Res. 101 (D3) (1996a) 6971-6977.

[10] Y. Guo, N.N. Barthakur, S. Bhartendu, Using atmospheric electrical conductivity as an urban air pollution indicator, J. Geophys. Res. 101 (D4) (1996b) 9197-9203.

[11] R. Gunn, Diffusion charging of atmospheric droplets by ions and the resulting combination coefficients, J. Meteorology 11 (1954) 339-347.

[12] R.G. Harrison, K.L. Aplin, Mid-nineteenth century smoke concentrations near
London, Atmos. Environ. 36 (2002) 4037.

13] R.G. Harrison, K.S. Carslaw, Ion-aerosol-cloud processes in the lower atmosphere, Rev. Geophys. 41 (3) (2003) 1012, http://dx.doi.org/10.1029 2002RG000114.

[14] R.G. Harrison, The global atmospheric electrical circuit and climate, Surv. Geophys. 25 (5-6) (2004) 441-484.

[15] R.G. Harrison, Urban smoke concentrations at Kew, London, 1898-2004 Environment 40 (18) (2006) 3327-3332.

[16] G. Hanrahan, in: Modelling of Pollutants in Complex Environmental Systems, Vol. 1, ILM Publications (UK), 2010.

[17] L.W. Horowitz, A.M. Fiore, G.P. Milly, R.C. Cohen, A. Perring, P.J. Wooldridge P.G. Hess, L.K. Emmons, J.-F. Lamarque, Observational constraints on the chemistry of isoprene nitrates over the eastern United States, J. Geophys. Res. Atmos. 112 (2007). D12S08.

[18] W.A. Hoppel, Ion-aerosol attachment coefficients, ion depletion, and the charge distribution on aerosols, J. Geophys. Res. 90 (D4) (1985) 5917-5923.

[19] M.E. Jenkin, K.C. Clemitshaw, Ozone and other secondary photochemica pollutants: chemical processes governing their formation in the planetary boundary layer, Atmos. Environ. 34 (2000) 2499-2527.

[20] J. Kirkby, J. Duplissy, K. Sengupta, C. Frege, H. Gordon, C. Williamson, M. Heinritzi, M. Simon, C. Yan, J. Almeida, J. Tröstl, T. Nieminen, I.K. Ortega, R. Wagner, A. Adamov, A. Amorim, A.-K. Bernhammer, F. Bianchi, M. Breitenlechner, S. Brilke, X. Chen, J. Craven, A. Dias, S. Ehrhart, R.C. Flagan, A. Franchin, C. Fuchs, R. Guida, J. Hakala, C.R. Hoyle, T. Jokinen, H. Junninen, J. Kangasluoma, J. Kim, M. Krapf, A. Kürten, A. Laaksonen, K. Lehtipalo, V. Makhmutov, S. Mathot, U. Molteni, A. Onnela, O. Peräkylä, F. Piel, T. Petäjä, A.P. Praplan, K. Pringle, A. Rap, N.A.D. Richards, I. Riipinen, M.P. Rissanen, L. Rondo, N. Sarnela, S. Schobesberger, C.E. Scott, J.H. Seinfeld, M. Sipilä, G. Steiner, Y. Stozhkov, F. Stratmann, A. Tomé, A. Virtanen, A.L. Vogel, A.C. Wagner, P.E. Wagner, E. Weingartner, D. Wimmer, P.M. Winkler, P. Ye, X. Zhang, A. Hansel, J. Dommen, N.M. Donahue, D.R. Worsnop, U. Baltensperger, M. Kulmala, K.S. Carslaw, J. Curtius, Ion-induced nucleation of pure biogenic particles, Nature 533 (2016) 521, http://dx.doi.org/10.1038/ nature17953.

[21] M. Kulmala, V.-M. Kerminen, T. Anttila, A. Laaksonen, C.D. O'Dowd, Organic aerosol formation via sulphate cluster activation, J. Geophys. Res. 109 (2004) http://dx.doi.org/10.1029/2003JD003961. D04205.

[22] V.A. Lanz, A.S.H. Prévôt, M.R. Alfarra, S. Weimer, C. Mohr, P.F. DeCarlo M.F.D. Gianini, C. Hueglin, J. Schneider, O. Favez, B. D'Anna, C. George U. Baltensperger, Characterization of aerosol chemical composition with aerosol mass spectrometry in Central Europe: an overview, Atmos. Chem. Phys. 10 (2010) 10453-10471, http://dx.doi.org/10.5194/acp-10-10453-2010.

[23] I.D. Longley, D.W.F. Inglis, M.W. Gallagher, P.I. Williams, J.D. Allan, H. Coe Using $\mathrm{NO}_{\mathrm{x}}$ and $\mathrm{CO}$ monitoring data to indicate fine aerosol number concentrations and emission factors in three UK conurbations, Atmos. Environ. 39 (2005) 5157-5169.

[24] D.J., McKee (Ed.), Tropospheric Ozone: Human Healthand Agricultural Impacts, Lewis Publishers, Boca Raton, FL, 1994.

[25] D. Moller, Chemistry of the Climate System, Walter de Gruyter GmbH \& Co, KG, Berlin/New York, 2010.

[26] National Research Council - NRC, Rethinking the Ozone Problem in Urban and Regional Air Pollution, Washington DC, National Academy Press, 1991.

[27] J. Niemelä, J. Breuste, T. Elmqvist, G. Guntenspergen, P. James, N. MacIntyre, Introduction, in: J. Niemeä, J. Breuste, T. Elmqvist, G. Guntenspergen, P. James, N. MacIntyre (Eds.), Urban Ecology: Patterns, Processes and Applications, Oxford Biology, Oxford, UK, 2011.

[28] D.M. Pinto, J.D. Blande, S.R. Souza, A.M. Nerg, J.K. Holopainen, Plant volatile organic compounds (VOCs) in ozone (O3) polluted atmospheres: the ecological effects, J. Chem. Ecol. 36 (2010) 22-34, http://dx.doi.org/10.1007/s10886 009-9732-3.

[29] J.-P. Putaud, R. van Dingenen, A. Alastuey, H. Bauer, W. Birmili, J. Cyrys, H. Flentje, S. Fuzzi, R. Gehrig, H.C. Hansson, R.M. Harrison, H. Herrmann, R. Hitzenberger, C. Hüglin, A.M. Jones, A. Kasper-Giebl, G. Kiss, A. Kousa T.A.J. Kuhlbusch, G. Loschau, W. Maenhaut, A. Molnar, T. Moreno, J. Pekkanen, C. Perrino, M. Pitz, H. Puxbaum, X. Querol, S. Rodriguez, I. Salma, J. Schwarz, J. Smolik, J. Schneider, G. Spindler, H. ten Brink, J. Tursic, M. Viana, A. Wiedensohler, F. Raes, A European aerosol phenomenology - 3: physica and chemical characteristics of particulate matter from 60 rural, urban, and kerbside sites across Europe, Atmos. Environ. 44 (2010) 1308-1320, http:// dx.doi.org/10.1016/j.atmosenv.2009.12.011.

[30] Z.D. Ristovski, T. Suni, M. Kulmala, M. Boy, N.K. Meyer, J. Duplissy, A. Turnipseed, L. Morawska, U. Baltensperger, The role of sulphates and organic vapours in growth of newly formed particles in a eucalypt forest Atmos. Chem. Phys. 10 (2010) 2919-2926, http://dx.doi.org/10.5194/acp-102919-2010.

[31] J.D. Scargle, Studies in astronomical time series analysis. II. Statistical aspects of spectral analysis of unevenly spaced data, Astronomical J. 263 (1982) 835-853.

[32] C. Serrano, A.H. Reis, R. Rosa, P.S. Lucio, Influences of cosmic radiation, artificial radioactivity and aerosol concentration upon the fair-weather atmospheric electric field in Lisbon (1955-1991), Atmos. Res. 81 (2006) 236.

[33] J.J. Shah, T. Nagpal, C.J. Brandon, Urban Air Quality Management Strategy in Asia Guidebook, The World Bank, Washington D.C, 1997.

[34] B. Shoelson. www.mathworks.com/matlabcentral/fileexchange/993lombscargle-m, 2001. 
[35] H.G. Silva, R. Conceição, M. Melgão, K. Nicoll, P.B. Mendes, M. Tlemçani, A.H. Reis, R.G. Harrison, Atmospheric electric field measurements in urban environment and the pollutant aerosol weekly dependence, Environ. Res. Lett. 9 (2014) 114025, http://dx.doi.org/10.1088/1748-9326/9/11/114025.

[36] H.G. Silva, R. Conceição, M.D. Wright, J.C. Matthews, S.N. Pereira, D.E. Shallcross, Aerosol hygroscopic growth and the dependence of atmospheric electric field measurements with relative humidity, J. Aerosol Sci. 85 (2015a) 42-51, http://dx.doi.org/10.1016/j.jaerosci.2015.03.003.

[37] H.G. Silva, J.C. Matthews, R. Conceição, M.D. Wright, A.H. Reis, D.E. Shallcross, Modulation of urban atmospheric electric field measurements with the wind direction in Lisbon (Portugal), J. Phys. Conf. Ser. 646 (2015b) 012013.

[38] H. Tammet, U. Hõrrak, L. Laakso, M. Kulmala, Factors of air ion balance in a coniferous forest according to measurements in Hyytiälä, Finl. Atmos. Chem. Phys. 6 (2006) 3377-3390.

[39] M. Tasic, et al., Physic-Chemical characterization of PM10 and PM2.5 particles in the Belgrade urban area, Act. Chem. Slov. 53 (2006) 401-405.

[40] O. Tchepel, C. Borrego, Frequency analysis of air quality time series for traffic related pollutants, J. Environ. Monit. 12 (2010) 544-550.

[41] V. Verstreng, G. Myhre, H. Fagerli, S. Reis, L. Tarrasón, Twenty-five years of continuous sulphur dioxide emission reduction in Europe, Atmos. Chem. Phys. 7 (2007) 3663-3681.

[42] M.D. Wright, N.K. Holden, D.E. Shallcross, D.L. Henshaw, Indoor and outdoor atmospheric ion mobility spectra, diurnal variation, and relationship with meteorological parameters, J. Geophys. Res. Atmos. 119 (2014), http:// dx.doi.org/10.1002/2013JD020956.

[43] Q. Zhang, C.O. Stanier, M.R. Canagaratna, J.T. Jayne, D.R. Worsnop, S.N. Pandis, J.L. Jimenez, Insights into the chemistry of new particle formation and growth events in pittsburgh based on aerosol mass spectrometry, Environ. Sci. Technol. 38 (2004) 4797-4809, http://dx.doi.org/10.1021/es035417u. 